\title{
HUBUNGAN MENARCHE TERHADAP MENOPAUSE DI KECAMATAN LALABATA KAB. SOPPENG SULAWESI SELATAN
}

\author{
${ }^{1}$ Auliah Ratna \\ ${ }^{2}$ Hermie M. M. Tendean \\ ${ }^{2}$ Eddy Suparman
}

\author{
${ }^{1}$ Kandidat Skripsi Fakultas Kedokteran Universitas Sam Ratulangi Manado \\ ${ }^{2}$ Bagian Obstetri dan Ginekologi Fakultas Kedokteran Universitas Sam Ratulangi \\ Manado \\ Email: Auliah.Ratna@yahoo.com
}

\begin{abstract}
Advanced age meaning the progressive change in organism that have reached maturity, these changes are general andirreversible (can not be returned). There are fundamental problems faced by older women that is menopause. As for the factors that can affect their menopause, one of them is menarche. Where the faster someone get of menarche then will go on the age of menopause late, as well as otherwise, the above are encouraging authors to investigate the relationship of menarche to menopause in the district lalabata kab.Soppeng (Sul-Sel).
\end{abstract}

Objective : Describing the influence of menarche age to menopause age in postmenopausal women in the village of Lalabata-Soppeng (Sul-Sel) in 2013.

Methods: This study is an analytical survey with a cross sectional approache. The respondents of this study were 67 postmenopausal women with simple regression linear analise.

Results and conclusions :There is an influence of menarche age to menopause age in menopausal women. The younger a first menstruation, the older or the longer she is entering the age of menopause. With regretion modle: $y=62,008-0,911 x$ ( $y=$ age menopause and $\mathrm{x}=$ age menarche). Like the results that age of menarche 8 years old will go on menopause 55 years old,then menarche age of 13 years old will go on menopause age of 50 years old. while the age of menarche 19 years will go on menopause age of 45 years.

Keywords : The age of menarche and menopause.

\footnotetext{
Abstrak: Usia lanjut mengandung pengertian adanya perubahan yang progresif pada organisme yang telah mencapai kemasakan, perubahan ini bersifat umum dan irreversible (tidak dapat kembali). Ada masalah pokok yang dihadapi wanita lanjut usia yaitu menopause. Adapun faktor-faktor yang dapat mempengaruhi menopause, salah satu diantaranya ialah menarche. Dimana semakin cepat seseorang mendapatkan
} 
menarche maka akan memasuki usia menopause lambat, begitupula sebaliknya. Halhal diatas yang mendorong penulis untuk meneliti Hubungan Menarche Terhadap Menopause di Kecamatan Lalabata Kab. Soppeng (Sul-Sel).

Tujuan: Mengetahui hubungan usia menarche terhadap usia menopause pada wanita menopause di Kecamatan Lalabata Kab. Soppeng tahun 2013.

Metode: Penelitian ini adalah penelitian analitik dengan pendekatan cross sectional. Sampel penelitian ini adalah wanita menopause sebanyak 67 responden dengan analisa regresi linear sederhana.

Hasil \& Kesimpulan: Ada pengaruh usia menarche terhadap usia menopause pada wanita menopause. Makin dini menarche terjadi, makin lambat menopause timbul. Model regresi yang diperoleh : $\mathrm{y}=62,008-0,911 \mathrm{x}$. Jika menarche 8 tahun akan memasuki usia menopause 55 tahun, usia menarche 13 tahun akan memasuki usia menopause 50 tahun sedangkan usia menarche 19 tahun akan memasuki usia menopause 45 tahun.

Kata Kunci: Usia Menarche dan menopause.

\section{PENDAHULUAN}

Adapun siklus hidup seorang wanita secara normal akan mengalami menarche (usia 11-15 tahun) dengan rata-rata menarche 13 tahun, masa reproduksi (usia 15-46 tahun) dan menopause (usia 50-51 tahun). Usiamenopause di Indonesia relatif sama dengan di Negara-negara barat dan Asia lainnya, yaitu sekitar 50 tahun. ${ }^{1}$

Menjadi tua adalah suatu proses yang merupakan bagian dari kehidupan seseorang, dan sudah terjadi sejak konsepsi dalam kandungan yang berlangsung terus sepanjang kehidupan. Usia lanjut mengandung pengertian adanya perubahan yang progresif pada organisme yang telah mencapai kemasakan, perubahan ini bersifat umum dan irreversible (tidak dapat kembali). ${ }^{2}$

Menarche adalah saat terjadinya perdarahan pertama dari uterus yang terjadi pada seorang wanita atau sering disebut sebagai menstruasi pertama,.Menarche merupakan proses pertumbuhan yang terjadi pada wanita. ${ }^{3}$ Terjadinya menarche dapat dipengaruhi oleh banyak faktor, antara lain: faktor hormonal, faktor genetic, faktor keadaan gizi, faktor lingkungan, faktor aktivitas fisik dan faktor rangsangan psikis. Menarche terjadi rata-rata umur 13 tahun, perimenarche $11-15$ tahun. $^{4}$

Menarche merupakan menstruasi yang pertama kali dialami wanita, dimana secara fisik ditandai dengan keluarnya darah dari vagina akibat peluruhan lapisan endometrium. ${ }^{3}$

Menopause didefinisikan secara klinis sebagai waktu di mana seorang wanita tidak mengalami menstruasi selama satu tahun, yang diawali dengan tidak teraturnya periode menstruasi dan diikuti dengan berhentinya periode menstruasi. Menopause merupakan fase dalam kehidupan seorang wanita yang ditandai dengan berhentinya masa subur. ${ }^{5}$

Penyebab menopause adalah matinya (burning out) ovarium.Sepanjang kehidupan seksual seorang wanita, kira-kira 400 folikel primordial tumbuh menjadi folikel matang dan berovulasi, dan beratus-ratus dari ribuan ovum berdegenerasi. Pada usia 45 tahun, hanya tinggal beberapa folikel primordial yang akan dirangsang oleh FSH dan LH, dan produksi estrogen dari ovarium berkurang sewaktu jumlah folikel primordial mencapai nol. Lihat pada gambar II. Ketika produksi estrogen turun di bawah nilai kritis, estrogen tidak lagi dapat menghambat produksi gonadotropin FSH dan LH. 
Sebaliknya, gonadotropin FSH dan LH (terutama FSH) diproduksi sesudah menopause dalam jumlah besar dan kontinu, tetapi ketika folikel primordial yang tersisa menjadi atretik, produksi estrogen oleh ovarium turun secara nyata menjadi nol. ${ }^{6}$

Banyak faktor yang berhubungan dengan usiamenopause. Beberapa faktor tersebut diantaranya yaitu usia pertama kali menstruasi (menarche), menurut Reitz wanita yang terlambat mendapatkan menstruasi pada usia 16 atau 17 tahun, justru akan mengalami menopause lebih dini, sedangkan mereka yang haid lebih dini seringkali akan mengalaminya sampai pada usia mencapai 50 tahun. Ada pola keluarga yang berlaku secara umum, bagi seorang wanita yang ibu atau kakak perempuannya lebih dini mengalami menopause maka ia juga cenderung mengalami hal yang sama, begitu pula sebaliknya.

Berdasarkan latar belakang tersebut dan mengingat tingginya prevalensi usia lanjut di Kecamatan Lalabata Kab.Soppeng (Sul-Sel), maka penulis tertarik untuk mengetahui lebih lanjut hunungan menarche terhadap menopause khususnya pada wanita menopause di Kecamatan lalabata, Kab.Soppeng (Sul-Sel).

\section{METODE PENELITIAN}

Penelitian ini termasuk dalam ruang lingkup Obstetry dan Gynecology yang di lakukan di Kecamatan lalabata Kab.Soppeng (Sul-Sel) pada bulan Oktober-Desember 2013. Jenis penelitian ini adalah epidemiologi analitik dengan desain cross sectional.

\section{Populasi Target}

Dalam penelitian ini adalah semua wanitayang sudah mengalami menopause di Kecamatan Lalabata Kab.Soppeng (SulSel).Ditetapkan besar sampel 67 orang, Teknik pengambilan sampel dalam penelitian ini adalah dengan menggunakan non-probability sampling design. Karena subyek dalam populasi dikumpulkan tidak secara acak dimana tidak semua orang dalam populasi dapat menjadi sampel. Cara pengambilan sampel dengan menggunakan purposive sampling. ${ }^{8}$ Sampel yang diambil telah memenuhi kriteria, yaitu bersedia menjadi responden, para wanita usia dewasa yang sudah mengalami menopause, bukan keadaan menopause yang buatan atau karena operasi.
Variabel bebas dalam penelitian ini ialah Menarche dan variable Terikatnya ialah Menopause. Instrumen Penelitian ini yaitu menggunakan alat penelitian berupa wawancara kuesioner pencatatan data yang selanjutnya setelah seluruh data yang terkumpul diolah dengan menggunakan SPSS (Statistical Program for Social Science) versi 20.0. ${ }^{8}$

\section{Analisis Data}

Analisi data yang dilakukan yaitu analisis bivariat yaitu untuk melihat hubungan kedua variabel independen dan variable dependen. Analisis data dilakukan dengan menggunakan Uji regresi linear sederhana. ${ }^{8}$

\section{HASIL}

A. Distribusi Responden Berdasarkan Karakteristik Responden di Kecamatan Lalabata Kabupaten Soppeng (Sulawesi Selatan).

\section{Distribusi Responden Berdasarkan Umur Responden}

Dari Tabel 1 Diketahui bahwa umur responden terbanyak adalah 55-64 tahun dengan jumlah 37 responden $(55,2 \%)$ dan yang terendah adalah umur responden 45-54 tahun dengan jumlah 13 responden $(19,4 \%)$. Rata-rata umur responden 59,91 tahun $=59$ tahun atau 60 tahun.

Tabel 1. Umur Responden

\begin{tabular}{cccc}
\hline & & $\mathrm{n}$ & $\%$ \\
\hline Umur & 45-54 tahun & 13 & 19,4 \\
& 55-64 tahun & 37 & 55,2 \\
& $>65$ tahun & 17 & 25,4 \\
& Total & 67 & 100,0 \\
& 45-54 tahun & 13 & 19,4 \\
\hline
\end{tabular}

\begin{tabular}{lcccc}
\hline & $\mathrm{N}$ & Minimum & Maximum & Mean \\
Umur & 67 & 50 & 71 & 59.91 \\
\hline
\end{tabular}

\section{Distribusi Responden Berdasarkan Umur Menopause.}

Dari Tabel 2 Diketahui bahwa umur usia menopause terbanyak adalah umur 45-54 tahun dengan jumlah 49 responden $(73,1 \%)$ dan yang 
paling terendah adalah usia menopause 25-34 tahun dengan jumlah 1 responden (1,5\%).

Tabel 2. Umur menopause Responden

\begin{tabular}{cccc}
\hline & & $\mathrm{n}$ & $\%$ \\
\hline \multirow{2}{*}{ Umur } & 25-34 tahun & 1 & 1,5 \\
& 35-44 tahun & 7 & 10,4 \\
45-54 tahun & 49 & 73,1 \\
55-64 tahun & 10 & 14,9 \\
Total & 67 & 100 \\
\hline
\end{tabular}

\begin{tabular}{ccccc}
\hline & N & Min. & Max & Mean \\
\hline Menopause & 67 & 30 & 60 & 49.91 \\
\hline
\end{tabular}

Distribusi Responden Berdasarkan Tingkat Pendidikan.

Dari Tabel 3 diketahui bahwa Tingkat pendidikan responden terbanyak adalah tamat SD yaitu 27 responden (40,3\%), dan yang terendah adalah Tidak sekolah dengan jumlah 2 responden $(3,0 \%)$.

Tabel 3. Tingkat Pendidikan Responden

\begin{tabular}{cccc}
\hline & & $\mathrm{n}$ & $\%$ \\
\hline Pendidikan & SD & 27 & 40.3 \\
& SMP & 20 & 29.9 \\
SMA & 11 & 16.4 \\
Perguruan & 7 & 10.4 \\
Tinggi & 2 & 3.0 \\
\hline
\end{tabular}

B. Distribusi Responden Berdasarkan Faktor-Faktor yang Mempengaruhi Menopause.

\section{Distribusi Responden Berdasarkan Hubungan Status Pernikahan dengan Menopause.}

Dari Tabel 4 di atas bahwa yang memiliki status perkawinan terbanyak adalah yang telah menikah dengan jumlah 47 responden (95,9\%) dengan usia menopause 45-54 tahun. Dan terendah adalah tidak menikah jumlah 2 responden $(4,1 \%)$ dengan usia menopause 45-54 tahun.
Tabel 4. Status Pernikahan dengan Menopause

\begin{tabular}{|c|c|c|c|c|c|c|c|c|c|c|}
\hline \multirow{3}{*}{$\begin{array}{c}\text { Status } \\
\text { pernikahan }\end{array}$} & \multicolumn{8}{|c|}{ Menopause } & \multicolumn{2}{|c|}{ Total } \\
\hline & \multicolumn{2}{|c|}{$25-34$} & \multicolumn{2}{|c|}{$35-44$} & \multicolumn{2}{|c|}{$45-54$} & \multicolumn{2}{|c|}{$55-64$} & \multirow[b]{2}{*}{$\mathrm{n}$} & \multirow[b]{2}{*}{$\%$} \\
\hline & $\mathrm{n}$ & $\%$ & $\mathrm{n}$ & $\%$ & $\mathrm{n}$ & $\%$ & $\mathrm{n}$ & $\%$ & & \\
\hline Menikah & 1 & 100 & 7 & 100 & 47 & 95,9 & 10 & 100 & 65 & 97 \\
\hline T. & 0 & 0 & 0 & 0 & 2 & 4,1 & 0 & 0 & 2 & 3 \\
\hline Menikah & & & & & & & & & & \\
\hline Total & 1 & 100 & 7 & 100 & 49 & 100 & 10 & 100 & 67 & 100 \\
\hline
\end{tabular}

\section{Distribusi Responden Berdasarkan Hubungan Status Pekerjaan dengan Menopause.}

Dari Tabel 5 di atas bahwa responden IRT (Ibu Rumah Tangga) lebih banyak dibandingkan yang lainnya, yaitu 33 responden (67,3\%) dengan usia menopause 45-54 tahun. Dan yang terendah adalah PNS (aktif) jumlah 1 responden (2,0\%) dengan usia menopause 45-54 tahun.

Tabel 5. Status Pekerjaan dengan Menopause

\begin{tabular}{cccccccccccc}
\hline Pekerjaan & \multicolumn{1}{c}{ Menopause } & & \multicolumn{2}{c}{ Total } \\
& \multicolumn{1}{c}{$25-34$} & \multicolumn{2}{c}{$35-44$} & $45-54$ & \multicolumn{2}{c}{$55-64$} & & \\
& \multicolumn{1}{c}{} & & & & & & & \\
& $\mathrm{n}$ & $\%$ & $\mathrm{n}$ & $\%$ & $\mathrm{n}$ & $\%$ & $\mathrm{n}$ & $\%$ & $\mathrm{n}$ & $\%$ \\
\hline IRT & 1 & 100 & 4 & 57,1 & 33 & 67,3 & 9 & 90,0 & 47 & 70,1 \\
Wiraswasta & 0 & 0 & 2 & 28,6 & 5 & 10,2 & 0 & 0 & 7 & 10,4 \\
Pensiunan & 0 & 0 & 0 & 0 & 10 & 20,4 & 0 & 0 & 10 & 14,9 \\
PNS (aktif) & 0 & 0 & 1 & 14,3 & 1 & 2,0 & 1 & 10,0 & 3 & 4,5 \\
Total & 1 & 100 & 7 & 100 & 49 & 100 & 10 & 100 & 67 & 100 \\
\hline
\end{tabular}

\section{Distribusi Responden Berdasarkan Hubungan Jumlah Anak dengan Menopause di Kecamatan Lalabata Kabupaten Soppeng.}

Dari Tabel 6 di atas bahwa jumlah anak terbanyak ialah $<4$ orang, yaitu 28 responden $(57,1 \%)$ dengan usia menopause $45-54$ tahun. Dan terendah $<4$ anak jumlah 1 responden (10\%) dengan usia menopause 55-64 tahun.

Tabel 6. Jumlah Anak dengan Menopause

\begin{tabular}{cccccccccccc}
\hline $\begin{array}{c}\text { Jumlah } \\
\text { Anak }\end{array}$ & \multicolumn{9}{c}{ Menopause } & & \multicolumn{2}{c}{ Total } \\
& $25-34$ & \multicolumn{2}{c}{$35-44$} & $45-54$ & $55-64$ & & \\
& & & & & & & & & \\
& & $\%$ & $\mathrm{n}$ & $\%$ & $\mathrm{n}$ & $\%$ & $\mathrm{n}$ & $\%$ & $\mathrm{n}$ & $\%$ \\
\hline$>4$ anak & 1 & 100 & 2 & 28,6 & 17 & 34,7 & 9 & 90 & 29 & 43,3 \\
$<4$ anak & 0 & 0 & 5 & 71,4 & 28 & 57,1 & 1 & 10 & 34 & 50,7 \\
T. Anak & 0 & 0 & 0 & 0 & 4 & 8,2 & 0 & 0 & 4 & 6 \\
Total & 1 & 100 & 7 & 100 & 49 & 100 & 10 & 100 & 67 & 100 \\
\hline
\end{tabular}


Distribusi Responden Berdasarkan Hubungan Penggunaan Kontrasepsi dengan Menopause.

Dari Tabel 7 Diketahui bahwa jumlah pemakaian kontrasepsi terbanyak adalah menggunakan kontrasepsi hormonal, yaitu 23 responden (46,9\%) dengan usia menopause 44-54 tahun. Dan terendah adalah tidak memakai kontrasepsi dengan jumlah 1 responden (10\%) dengan usia menopause 55-64 tahun.

Tabel 7. Penggunaan Kontrasepsi dengan Menopause

\begin{tabular}{|c|c|c|c|c|c|c|c|c|c|c|}
\hline \multirow[t]{3}{*}{ Kontrasepsi } & \multicolumn{8}{|c|}{ Menopause } & \multicolumn{2}{|c|}{ Total } \\
\hline & \multicolumn{2}{|c|}{$25-34$} & \multicolumn{2}{|c|}{$35-44$} & \multicolumn{2}{|c|}{$45-54$} & \multicolumn{2}{|c|}{$55-64$} & \multirow[b]{2}{*}{$\mathrm{n}$} & \multirow[b]{2}{*}{$\%$} \\
\hline & $\mathrm{n}$ & $\%$ & $\mathrm{n}$ & $\%$ & $\mathrm{n}$ & $\%$ & $\mathrm{n}$ & $\%$ & & \\
\hline Hormonal & 0 & 0 & 5 & 71,4 & 23 & 46,9 & 5 & 50 & 33 & 49,3 \\
\hline B.hormonal & 0 & 0 & 1 & 14,3 & 13 & 26,5 & 4 & 40 & 18 & 26,9 \\
\hline T. Pakai & 1 & 100 & 1 & 14,3 & 13 & 26,5 & 1 & 10 & 16 & 23,9 \\
\hline Total & 1 & 100 & 7 & 100 & 49 & 100 & 10 & 100 & 67 & 100 \\
\hline
\end{tabular}

\section{Distribusi Responden Berdasarkan Hubungan Usia Melahirkan Anak Terakhir dengan Menopause.}

Dari Tabel 8 Diketahui bahwa usia melahirkan anak terakhir yang terbanyak adalah $<40$ tahun, yaitu 36 responden (73,5\%) dengan usia menopause 45-54 tahun. Dan yang terendah adalah $\geq 40$ tahun dengan usia menopause 35-44 tahun dengan jumlah 1 responden (14,3\%).

Tabel 8. Usia Melahirkan dengan Menopause

\begin{tabular}{|c|c|c|c|c|c|c|c|c|c|c|}
\hline \multirow{3}{*}{$\begin{array}{c}\text { Usia } \\
\text { terakhir } \\
\text { melahirkan }\end{array}$} & \multicolumn{8}{|c|}{ Menopause } & \multicolumn{2}{|c|}{ Total } \\
\hline & \multicolumn{2}{|c|}{$25-34$} & \multicolumn{2}{|c|}{$35-44$} & \multicolumn{2}{|c|}{$45-54$} & \multicolumn{2}{|c|}{$55-64$} & \multirow[b]{2}{*}{$\mathrm{n}$} & \multirow[b]{2}{*}{$\%$} \\
\hline & $\mathrm{n}$ & $\%$ & $\mathrm{n}$ & $\%$ & $\mathrm{n}$ & $\%$ & $\mathrm{n}$ & $\%$ & & \\
\hline$>40$ tahun & 0 & 0 & 1 & 14,3 & 9 & 18,4 & 3 & 30 & 13 & 19,4 \\
\hline$\overline{<}<0$ tahun & 1 & 100 & 6 & 85,7 & 36 & 73,5 & 7 & 70 & 50 & 74,6 \\
\hline T. Anak & 0 & 0 & 0 & 0 & 4 & 8,2 & 0 & 0 & 4 & 6 \\
\hline Total & 1 & 100 & 7 & 100 & 49 & 100 & 10 & 100 & 67 & 100 \\
\hline
\end{tabular}

\section{Distribusi Responden Berdasarkan Hubungan Menarche dengan Menopause.}

Dari Tabel 9 Diketahui bahwa usia minimum menarche 8 tahun, usia maksimum menarche 19 tahun dan rata-rata usia menarche adalah 13,28 = 13 tahun. Sedangkan usia minimum Menopause 30 tahun, usia maximum menopause 60 tahun, dan rata-rata $49,91=49$ atau 50 tahun. Berdasarkan uji regresi linear diperoleh persamaan garis sebagai berikut: $\mathrm{Y}=62,008-0,911 \mathrm{X}$.

Dimana $\mathrm{y}=$ usia menopause, $\mathrm{x}=$ usia menarche.
Jika $\mathrm{X}=8$ maka nilai $\mathrm{Y}=62,008-0,911 * 8=54,72$ (55 tahun)

Jika $\mathrm{X}=13$ maka nilai $\mathrm{Y}=62,008-0,911 * 13=$ 50,165 (50 tahun)

Jika $\mathrm{X}=19$ maka nilai $\mathrm{Y}=62,008-0,911 * 19=$ 44,699 (45 tahun).

Tabel 9. Menarche dengan Menopause

\begin{tabular}{|c|c|c|c|c|c|c|c|c|c|c|}
\hline \multirow[t]{3}{*}{ Menarche } & \multicolumn{8}{|c|}{ Menopause } & \multicolumn{2}{|c|}{ Total } \\
\hline & \multicolumn{2}{|c|}{$25-34$} & \multicolumn{2}{|c|}{$35-44$} & \multicolumn{2}{|c|}{$45-54$} & \multicolumn{2}{|c|}{$55-64$} & \multirow[b]{2}{*}{$\mathrm{n}$} & \multirow[b]{2}{*}{$\%$} \\
\hline & $\mathrm{n}$ & $\%$ & $\mathrm{n}$ & $\%$ & $\mathrm{n}$ & $\%$ & $\mathrm{n}$ & $\%$ & & \\
\hline $7-8$ & 0 & 0 & 0 & 0 & 1 & 2,0 & 0 & 0 & 1 & 1,5 \\
\hline $9-10$ & 0 & 0 & 0 & 0 & 2 & 4,1 & 4 & 40,0 & 6 & 9,0 \\
\hline $11-12$ & 0 & 0 & 0 & 50,0 & 13 & 26,5 & 2 & 20,0 & 15 & 22,4 \\
\hline $13-15$ & 0 & 0 & 5 & 71,4 & 27 & 55,1 & 4 & 40,0 & 36 & 53,7 \\
\hline$>15$ & 1 & 100 & 2 & 28,6 & 6 & 12,2 & 0 & 0 & 9 & 13,4 \\
\hline \multirow[t]{2}{*}{ Total } & 1 & 100 & 7 & 100 & 49 & 100 & 10 & 100 & 67 & 100 \\
\hline & & $\mathrm{N}$ & \multicolumn{2}{|c|}{ Min } & Max & \multicolumn{2}{|c|}{ Mean } & \multicolumn{3}{|c|}{ Median } \\
\hline \multicolumn{2}{|c|}{ Menopause } & 67 & \multicolumn{2}{|c|}{30} & 60 & \multicolumn{2}{|c|}{49.91} & \multicolumn{3}{|c|}{50} \\
\hline \multicolumn{2}{|c|}{ Menarche } & 67 & \multicolumn{2}{|c|}{8} & 19 & \multicolumn{2}{|c|}{13.28} & \multicolumn{3}{|c|}{13} \\
\hline
\end{tabular}

\section{PEMBAHASAN}

Penelitian ini dilakukan pada wanita yang sudah mengalami menopause di Kecamatan Lalabata Kab.Soppeng (Sul-Sel) selama bulan November-Desember 2013.

Dari distribusi responden berdasarkan faktor-faktor yang mempengaruhi menopause berdasarkan status pernikahan pada Tabel 4 didapatkan bahwa yang telah menikah dengan jumlah 47 responden (95,9\%) dengan usia menopause 45-54 tahun. Dan terendah adalah tidak menikah jumlah 2 responden (4,1\%) dengan usia menopause 45-54 tahun. Berdasarkan teori mengatakan bahwa keadaan seorang wanita yang tidak menikah diduga mempengaruhi perkembangan psikis wanita tersebut. Mereka akan mengalami masa menopause lebih cepat dibanding dengan wanita telah menikah. ${ }^{7}$

Berdasarkan status pekerjaaan pada Tabel 5 didapatkan bahwa responden IRT (Ibu Rumah Tangga) lebih banyak dibandingkan yang lainnya, yaitu 33 responden $(67,3 \%)$ dengan usia menopause 45-54 tahun. Dan yang terendah adalah PNS (aktif) jumlah 1 responden (2,0\%) dengan usia menopause 45-54 tahun. Menurut teori mengatakan bahwa wanita yang bekerja akan mengalami menopause lebih cepat dibandingkan wanita tidak bekerja. ${ }^{7}$

Pada Tabel 6 berdasarkan jumlah anak, bahwa jumlah anak terbanyak ialah $<4$ orang, yaitu 
28 responden $(57,1 \%)$ dengan usia menopause 4554 tahun. Dan terendah $<4$ anak jumlah 1 responden (10\%) dengan usiamenopause 55-64 tahun. Menurut teori mengatakan bahwa Makin sering melahirkan makin lama wanita tersebut mengalami menopause. $^{9}$

Pada Tabel 7 berdasarkan penggunaan kontrasepsi, yang memakai kontrasepsi hormonal yaitu 23 responden (46,9\%) dengan usia menopause 44-54 tahun. Dan terendah adalah tidak memakai kontrasepsi dengan jumlah 1 responden (10\%) dengan usia menopause 55-64 tahun. Menurut teori mengatakan bahwa Pemakaian kontrasepsi, khususnya kontrasepsi hormonal, dimana cara kerjanya dengan menekan fungsi hormon dari indung telur, sehingga menopausenya lebih lama disbanding yang tidak mengguanakan kontrasepsi hormonal.

Pada Tabel 8 faktor berdasarkan usia melahirkan anak terakhir terbanyak pada umur $<40$ tahun yaitu 36 responden (73,5\%) dengan usia menopause 45-54 tahun. Dan yang terendah adalah $\geq 40$ tahun dengan usia menopause 35-44 tahun dengan jumlah 1 responden (14,3\%). Menurut teori mengatakan bahwa semakin tua umur melahirkan maka akan lebih lama memasuki usia menopause. ${ }^{7}$

Dari Tabel 9 Diketahui bahwa usia minimum menarche 8 tahun, usia maksimum menarche 19 tahun dan rata-rata usia menarche adalah 13,28 = 13 tahun. Sedangkan usia minimum Menopause 30 tahun, usia maksimum menopause 60 tahun, dan rata-rata $49,91=49$ atau 50 tahun. Data yang diperoleh dari analisis bivariat dikatakan bahwa pengaruh usia menarche terhadap usia menopause di Kecamatan Lalabata Kabupaten Soppeng diketahui nilai Sign. Berdasarkan hasil perhitungan yang didapat sebesar 0,003 dengan nilai $\alpha=0,05$ sehingga dapat disimpulkan bahwa Sign. <0,05 maka Ho ditolak dan Ha diterima. Dapat disimpulkan ada pengaruh usia menarche terhadap usia menopause pada wanita menopause, dengan kategori lemah berdasarkan nilai korelasi (Rxy) sebesar 0,358 kurang dari 0,5 artinya pengaruh lemah antara usia menarche terhadap usia menopause di Kecamatan Lalabata Kabupaten Soppeng. Pengaruh usia menarcheterhadap menopause sebesar $12,8 \%$ dan sisanya 87,2\% dipengaruhi oleh faktor-faktor yang lain. Ada pengaruh antara usiamenarche dengan usia saat terjadinya menopause. Makin dini menarche terjadi, makin lambat menopause timbul.Sebaliknya, makin lambat menarche terjadi makin cepat menopause timbul. Model regresi yang diperoleh : $\mathrm{y}=62,008$ 0,911x. Seperti yang tertera pada hasil bahwa dengan usia menarche 8 tahun akan memasuki usia menopause 55 tahun, usia menarche 13 tahun akan memasuki usia menopause 50 tahun sedangkan usia menarche 19 tahun akan memasuki usia menopause 45 tahun.

Menurut Speroff dan Reitz, wanita yang terlambat mendapatkan menstruasi, pada usia 16 atau 17 tahun, justru akan mengalami menopause lebih dini, sedangkan mereka yang haid lebih dini seringkali akan mengalaminya sampai pada usia mencapai 50 tahun. Ada pola keluarga yang berlaku secara umum, bagi seorang wanita yang ibu atau kakak perempuannya lebih dini mengalami menopause maka ia juga cenderung mengalami hal yang sama, begitu pula sebaliknya. Dikatakan bahwa usia menopause dini jika usia menopausenya sebelum usia <45 tahun dan ukuran normal menarche wanita U.S adalah 9,1-17,7 tahun dengan rata-rata 12,8 tahun. $^{10}$

Menurut Wiknjosastro menarche dini yaitu usia 10-11 tahun, Menarche normal yaitu usia 11-15 tahun, dan Menarche terlambat yaitu usia >15 tahun. ${ }^{5}$

Pendapat ini memiliki persamaan dengan hasil penelitian yang didapat. Dari pendapat di atas didapat bahwa semakin lama seorang wanita menarche semakin cepat ia akan memasuki usia menopause.

\section{KESIMPULAN}

Dari hasil penelitian diperoleh bahwa Usia Menarche responden minimum umur 8 tahun, maksimum umur 19 tahun dan rata-rata usia menarche adalah $13,8=13$ atau 14 tahun. Usia Menopause responden minimum 30 tahun, maksimum 60 tahun dan rata-rata usia menopause adalah $49,9=49$ atau 50 tahun. Dengan usia menarche 8 tahun akan memasuki usia menopause 55 tahun, usia menarche 13 tahun akan memasuki usia menopause 50 tahun sedangkan usia menarche 19 tahun akan memasuki usia menopause 45 tahun.

Ada pengaruh antara usia menarche dengan usia saat terjadinya menopause pada wanita menopause. Makin dini menarche terjadi, makin lambat menopause timbul. Dengan model regresi yang diperoleh : $y=62,008-0,911 x$. 


\section{SARAN}

Bagi pihak Kesehatan terutama Puskesmas tiap Kecamatan, agar lebih ditingkatkan sosialisasi tentang faktor-faktor yang dapat mempengaruhi menopause pada seorang wanita kepada seluruh penduduk wanita, baik melalui konseling ataupun penyuluhan.

Perlu dilakukan penelitian lebih lanjut tentang menarche dan menopause, misalnya dengan memasukkan faktor lain yang dapat mempengaruh menopause.

\section{UCAPAN TERIMA KASIH}

Ucapan terima kasih disampaikan pada Prof. dr. Hermie M. Tendean, Sp.OG(K), Prof.Dr. dr. Eddy Suparman Sp.OG(K), kedua Orang Tua, kakak Ismail Kadir dan semua pihak yang baik secara langsung maupun tidak langsung telah menumbuhkan ide atau gagasan dalam pemikiran penulis sehingga dapat menyelesaikan penelitian ini.

\section{DAFTAR PUSTAKA}

1. Prawiroharjo S. ilmu kandungan. Jakarta: PT. Bina Pustaka Sarwono Prawirohardjo; 2011.

2. Hawari. Al Qur'an: Ilmu Kedokteran Jiwa dan Kesehatan Jiwa. Yogyakarta :PT. Dana Bhakti Prima Yasa; 1996.

3. Agres V, Sunarto. Faktor Risiko Kejadian Menarche dini pada remaja di SMP N 30 Semarang. Jurnal Kedokteran Diponegoro, Vol.I, No.1. Semarang: FK UNDIP; 2012.

4. Tiyas M. Hubungan Antara Usia Saat Timbulnya Menarche dengan Usia Saat Terjadinya Menopause Wanita di Kecamatan Kartasura. Jurnal Kedokteran Muhammadiyah. Semarang: FK UNIMUS; 2001.

5. Rahmatika R, Sumarni, Prabandari F. Pengaruh Usia Menarche terhadap Usia Menopause Pada Wanita Menopause di Desa Jingkang Babakan. Jurnal Kebidanan YLPP, Vol.3, No.2. Purwokerto: Bidan Prada; 2012.

6. Guyton C, Hall E. Buku Ajar Fisiologi Kedokteran. Ed. 11. Jakarta: EGC; 2007 h.1075-6.

7. Safitri A. Beberapa factor yang Mempengaruhi Menopause pada Waita di kelurahan Titi Papan Kota Medan tahun 2009. (KTIS). Medan: FKM USU; 2009.
8. Sastroasmoro S, Ismael S. Dasar-dasar Metodologi Penelitian Klinis. Edisi ke-4. Jakarta: Sagung Seto; 2011.h.348-82.

9. Larasati T, Indah A. Kualitas Hidup Pada Wanita yang Sudah Memasuki Masa Menopause. Jurnal Psikolog Gunadarma. Jakarta: 2009.

10. Reitz, M \&Speroff L. Clinical Gynecologic Endocrinology and Infertility. Lippincott Williams \& Wilkins. USA; 2010. 